\title{
GRUPOS DE ESTUDO E APOIO À ADOÇÃO E O SUCESSO DAS ADOÇÕES
}

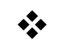 \\ Mariana de Oliveira Bortolatto \\ Universidade do Vale do Itajaí - UNIVALI - Brasil \\ Victória Niebuhr Loos \\ Universidade do Vale do Itajaí-UNIVALI - Brasil \\ Josiane da Silva Delvan \\ Universidade do Vale do Itajaí - UNIVALI - Brasil
}

\section{Resumo}

A adoção no Brasil sofreu alterações ao longo do tempo, ocorrendo de diferentes formas e representações. Buscando contribuir para uma mudança de perspectiva, surgiram os Grupos de Estudos e Apoio à Adoção. Este estudo procurou analisar o trabalho realizado por estes grupos verificando as possíveis contribuições da participação dos pais adotivos ou pretendentes à adoção, bem como analisar, mediante a perspectiva dos profissionais forenses, os possíveis fatores que contribuem para este sucesso. Esta é uma pesquisa de abordagem qualitativa, envolvendo como participantes pais implicados no processo de adoção e funcionários do Serviço Social Forense. A coleta dos dados foi realizada por meio da entrevista semiestruturada, cujos dados foram analisados posteriormente por meio de 4 categorias temáticas. Os resultados encontrados apontam que os grupos de estudos e apoio à adoção se constituem como uma importante rede de apoio emocional durante o tempo de espera pela adoção, na medida em que amenizam a ansiedade sentida pelos pretendentes e favorecem a troca de experiências e a construção de conhecimentos sobre o assunto. Os principais fatores contribuintes para o sucesso das adoções são a orientação, as trocas de experiências, a participação nas reuniões e em cursos preparatórios realizados pelo Poder Judiciário. Com este estudo, pôde-se concluir que as práticas de orientação e preparação à parentalidade, bem como as trocas de experiências possuem um papel significativo no sucesso das adoções. Também se concluiu que há diferenças entre as expectativas dos pretendentes e do Poder Judiciário em relação ao processo de adoção.

Palavras-chave: Adoção; Criança; Grupos de apoio.

\section{Introdução}

Ao longo da história, as adoções ocorreram de forma desordenada e sem controle por parte do Estado, atendendo as necessidades e direitos dos adultos (EBRAHIM, 2001; MAUX; DUTRA, 2010; NABINGER, 2010; GONÇALVES; BRANDÃO, 2011; WEBER, 2011). A literatura aponta que a adoção passou por diversas transformações no decorrer da história, e em cada momento ocorreu de uma forma e com um significado baseados nas crenças existentes na época. Por isso, Freire (2002) afirma que a adoção é um tema em constante 
mudança, repleto de representações e preconceitos.

Inicialmente o principal objetivo da adoção era dar a oportunidade de ter filhos ao casal que não poderia tê-los de forma tradicional. Atualmente, dentre as medidas de proteção à infância, a adoção é considerada como última alternativa. A criança ou o adolescente deve permanecer junto aos seus pais biológicos, sendo encaminhada para adoção apenas nos casos em que não está sendo cuidada e suas necessidades intelectuais, emocionais, alimentares e de saúde não estão sendo preservadas. Nestes casos, cabe ao Estado interferir priorizando as necessidades e direitos da criança, oferecendo-lhe uma família adotiva. A adoção de hoje é uma filiação estabelecida por lei, em que a criança adotada deve ser tratada e beneficiada da mesma forma que os filhos biológicos (NABINGER, 2010).

De acordo com Valente (2013), em pesquisa realizada pela Claves/Fiocruz em 2010 sobre o número de crianças em serviço de acolhimento no Brasil, 37.861 crianças encontramse acolhidas, sendo que destas 9,9\% estavam com a destituição do poder familiar concluída; 9,4\% com suspensão de poder familiar; 7,1\% legalmente encaminhados para a adoção; resultando em 26,4\% das crianças caminhando para um possível processo de adoção. Segundo Cavalcanti (2014), nos dados apresentados em 2010 no Cadastro Nacional de Adoção (CNA), $80,7 \%$ dos pretendentes à adoção somente aceitavam crianças com até 03 anos, sendo que apenas 7\% das crianças possuíam a idade nesta margem naquele ano. O número de crianças em abrigos e a quantidade de casais querendo adotar são significativos, porém o perfil procurado pelas famílias é quase sempre o mesmo. Conforme aponta Motta (2001, p.34): “o brasileiro ainda procura quase que exclusivamente crianças muito pequenas ou recémnascidas quando deseja adotar". As crianças em abrigos crescem enquanto esperam por uma família ou enquanto aguardam que a sua situação familiar se resolva, entrando para as estatísticas de adoções tardias (de crianças maiores).

Mediante a história e o contexto atual da adoção no Brasil, em busca de uma adoção que tenha por propósito conciliar os interesses dos pretendentes com a realidade e com o objetivo moderno da adoção, que é a busca pela garantia do direito de toda criança de crescer e ser educada em uma família, surgiram os Grupos de Estudos e Apoio à Adoção - GEAAs (WEBER, 2011). Formados pela sociedade civil, estes grupos constituem um movimento social, tendo como membros principais pessoas que fazem parte de famílias por adoção e profissionais ligados a esta área. Seus participantes têm o entendimento de que é necessário um maior processo de esclarecimento e conscientização sobre a relevância da legalidade do processo de adoção, bem como a facilitação e desentrave burocrático existente ao se tratar a questão do abandono de crianças em instituições de acolhimento. Atualmente, existem 
centenas destes grupos espalhados pelo país (GONÇALVES; BRANDÃO, 2011).

De acordo com Maux e Dutra (2010), os primeiros registros de pesquisas científicas sobre o processo de adoção datam da segunda metade da década de 80 do século XX. Em levantamento realizado por essas autoras, no período de 2000 a 2009 constam em dados estatísticos na Biblioteca Digital Brasileira de Teses e Dissertações (BDTD) 37 trabalhos referentes à adoção. De acordo com Huber e Siqueira (2010), os estudos referentes à adoção aumentam a cada ano, mas no Brasil estes não são suficientes para esclarecer as diversas indagações que se encontram na compreensão dos aspectos psicológicos envolvidos no processo da adoção.

Weber (2011) afirma que a sociedade nem sempre está preparada para tratar da adoção, pois existem muitos estereótipos e preconceitos dispersos na mídia e na opinião de muitas pessoas que tem pouco conhecimento sobre o tema. A relevância deste estudo é visível na medida em que esta poderá ser fonte de novos dados sobre o trabalho dos GEAAs, suas contribuições na mudança da realidade da adoção no Brasil, bem como as dificuldades enfrentadas após a adoção, que envolvem membros do grupo, pais adotivos e a comunidade em geral.

Em contato com os funcionários do Serviço Social forense de duas cidades do Vale do Itajaí, percebeu-se a demanda por investigações sobre adoção, especificamente sobre o funcionamento dos GEAAs e a sua contribuição no sucesso/dificuldades no processo de adoção. Este estudo procurou analisar o trabalho realizado por estes grupos; verificar as possíveis contribuições da participação nos mesmos, tanto para os pais adotivos quanto para os pretendentes à adoção; analisar, mediante a perspectiva dos profissionais forenses, os possíveis fatores que contribuem para o sucesso da adoção; descrever como acontece o estágio de convivência segundo os pais adotivos; analisar mediante as perspectivas destes, as contribuições para o sucesso das adoções.

\section{A adoção no Brasil}

$\mathrm{Na}$ Antiguidade, apesar de não haver uma legislação que determinasse como deveria ser a adoção, diferentes povos a praticaram, acolhendo crianças como filhos em suas famílias. De acordo com Mative e Rampazzo (2010), no Brasil em 1916, com o Código Civil, surgiu a primeira legislação referente à adoção. Mais tarde, nos anos de 1957 e 1965, houve algumas modificações na lei da adoção e em 1979, com a aprovação do Código de Menores, ocorreu um avanço em relação à proteção da criança e do adolescente na adoção, pois pela primeira 
vez foi estabelecido o Estágio de Convivência como necessário para a realização da adoção. Já em 1988 com a Constituição Federal, crianças e adolescentes passaram a ser vistas como sujeitos de direitos e prioridade do Estado, sendo dever de todos protegê-las zelando por seus direitos. A partir do Estatuto da Criança e do Adolescente (BRASIL, 1990), passaram a existir algumas exigências para que se possa adotar uma criança ou adolescente e, por fim, antes da sentença de adoção, exige-se um estágio de convivência por um prazo determinado pelo juiz. No dia 03 de agosto de 2009, foram sancionadas modificações no Estatuto da Criança e do Adolescente de 1990 sobre os procedimentos de adoção. Estas alterações tiveram por objetivo assegurar que as crianças e adolescentes possam conviver com seus familiares e em comunidade, sendo a adoção uma última opção.

A legislação brasileira prevê um trabalho de preparação, orientação e acompanhamento, tanto para os adotados quanto para os adotantes durante todo o processo de adoção. Entretanto, os pretendentes que entram no processo de adoção brasileiro atual encontram algumas dificuldades, entre elas a demora e a quantidade de procedimentos exigidos (documentação, entrevistas, avaliações, cursos); a falta de acompanhamento e orientação no período de espera (que pode estender-se por anos de acordo com o perfil desejado), bem como a adequação de suas expectativas à realidade brasileira e o enfrentamento de questões como motivação e preparação para a chegada da criança (BRASIL, 1990, 2014; SEQUEIRA; STELLA, 2014; MACÊDO, 2014). Também se percebe algumas preocupações dos adotantes que podem dificultar o processo de adoção, como o receio quanto à educação da criança, o medo em relação aos maus hábitos que esta tenha aprendido na instituição de acolhimento e a crença de que, adotando-se bebês e escondendo-se a adoção, diminuiriam as chances de terem maiores problemas. Geralmente, os pais que adotam crianças mais velhas são os que apresentam mais altruísmo, maturidade e estabilidade emocional; bem como experiência anterior com crianças (SANTOS et al., 2011).

Ebrahim (2001) refere que em pesquisas relacionadas à adoção tardia, grande parte da população apresenta preconceitos em relação a este tipo de adoção. Existe o medo em relação à educação destas crianças, os hábitos que elas já possuem e o fato de que não é possível esconder da criança que ela é adotada, razão pelas quais muitos querem adotar bebês, pois no Brasil, a adoção ainda é vista como uma solução para casais inférteis.

Diante do histórico da adoção no país e no mundo, bem como da mudança das classificações da adoção e do seu contexto atual, surgiram os GEAAs. Estes são organizações não governamentais que congregam interessados no procedimento adotivo e que almejam uma melhora da situação das crianças institucionalizadas, procurando promover, sempre que 
necessário, a adoção como forma de atender ao direito ao convívio familiar. Os GEAAs promovem também a troca de experiências entre os adotantes e os pretendentes. A maior parte deles é formada por pessoas que em algum momento tiveram a adoção como forma de constituição de sua família. A participação nestes grupos não é obrigatória, visto que existe a preparação psicossocial necessária indicada pela lei 12.010/2009 que é de responsabilidade do setor técnico das Varas da Infância e Juventude. Entretanto, em algumas comarcas, esta preparação indicada por lei é realizada em conjunto com os GEAAs, assim, durante o período em que a mesma ocorre, a participação no grupo torna-se obrigatória. Contudo, apesar de não ser sempre obrigatória a participação nos GEAAs, muitos destes grupos contribuem com discussões e abordagens dos temas referentes à adoção, portanto é recomendada a participação nos mesmos não só antes, mas durante e depois do processo de adoção (BERLINI, 2012).

Os GEAAs entre as funções já citadas, auxiliam também na orientação e aconselhamento de quem deseja se informar a respeito de adoção ou mesmo efetivá-la; bem como na divulgação e estímulo para outras pessoas capazes de adotar acolham uma criança. As trocas de experiências que promovem são responsáveis ainda por melhores resultados dos pais na tarefa de educar os filhos adotivos e prepará-los para um futuro digno (NABINGER, 2010). Os GEAAs estão vinculados a uma Associação Nacional de Apoio à Adoção (ANGAAD) que realiza encontros anuais entre os grupos (DIAS; SILVA; FONSECA, 2008).

De acordo com Campos (2012), a adoção também envolve um relacionamento entre pessoas, sendo necessário o estabelecimento de vínculos. Como todo relacionamento, este também está sujeito a alegrias e frustrações, sendo importante a preparação e acompanhamento dos pais após a adoção, em seu estágio de convivência com a criança. Algumas dificuldades em comum enfrentadas pelos pretendentes são destacadas por esta autora: o surgimento de comportamentos regressivos na criança, a agressividade aparentemente gratuita, sem correlação com fatos concretos, em particular contra a mãe adotiva. A busca da criança por traços em comuns com os pais adotivos, tentativas de imitar comportamentos dos pais e irmãos também são consideradas dificuldades. Assim como a construção do vínculo de filiação com atropelamento de etapas, a aquisição de novos hábitos e o fato do vínculo de filiação pode se dar de forma diferenciada.

Outras dificuldades incluem o fato da criança construir "um novo eu" (fantasias de invulnerabilidade, identificação com super-heróis e negação da sua história, fantasiar que os pais adotivos são os biológicos), existir sentimentos de vulnerabilidade, impotência e culpa por parte dos pais que tendem a achar que devem ser perfeitos. A mobilização de emoções 
intensas e carregadas de ambivalência por parte da criança e dos adotantes, e a criança mostrar-se muito "imatura" para certas coisas e muito "avançada" para outras, também podem se constituir como dificuldades (CAMPOS, 2012).

Após ocorrer a adoção, os pais adotivos podem encontrar algumas dificuldades relacionadas ao contexto socioeconômico e à existência ou não de uma rede de apoio para cuidar da criança, principalmente o apoio familiar, fundamental para o sucesso da adoção. Por outro lado, há também aspectos positivos que contribuem para o sucesso das adoções, como a "gravidez psicológica" denominação dada pelos pretendentes para o processo de preparação à adoção, que envolve desde o acompanhamento psicológico, participação em cursos e GEAAs e reflexões sobre o tema (SANTOS et al., 2011).

Atualmente a adoção é realizada obrigatoriamente por processo judicial. Estão aptos para adotar homens e mulheres maiores de 18 anos, independente do seu estado civil ou orientação sexual, desde que sejam, no mínimo, 16 anos mais velhos que o adotado e tenham condições de oferecer um ambiente adequado à criança/adolescente. Também não é permitido ter grau de parentesco direto com o adotante, como tio, avó, irmão, etc. A pessoa que deseja adotar deve ingressar com uma ação no Fórum de sua comarca, onde será realizada uma avaliação psicossocial, cujo resultado é encaminhado em forma de laudo para o Juiz da respectiva Vara de Infância e Juventude bem como ao Ministério Público. A partir disso é sentenciada a procedência do pedido ou não. Durante a tramitação deste processo, há um período de preparação psicossocial e jurídica, com cursos e orientações aos pretendentes. Logo após, estes passam por um estágio de convivência, que é um período estabelecido pelo juiz onde convivem os pretendentes e as crianças, mediante a orientação e acompanhamento da equipe forense para a consolidação da adoção (SILVA; MESQUITA; CARVALHO, 2010; KIRCH; COPATT, 2014). A participação nos GEAAs não é obrigatória por lei e por ser um grupo de reflexão aberto ao público, qualquer pessoa pode participar, independente de ter iniciado o processo de adoção.

\section{Metodologia}

Este estudo caracterizou-se como exploratório de campo e de abordagem qualitativa. (MINAYO, 2010). Participaram do estudo sete pessoas que adotaram crianças e que participaram dos GEAAs em uma cidade da Região do Vale do Itajaí. Para a escolha dos entrevistados, estabeleceu-se como critério que deveriam ter adotado uma ou mais crianças nos últimos cinco anos, podendo ou não ter filhos biológicos. Como critérios de exclusão para 
a participação estão as pessoas que não participaram dos GEAAs ou que devolveram a criança e as pessoas que não participaram do estágio de convivência.

Também foram entrevistadas três assistentes sociais e três psicólogos do Serviço Social Forense de duas cidades da Região do Vale do Itajaí, visto que estes participam do processo de adoção e do estágio de convivência, podendo apontar os possíveis fatores que contribuem para o sucesso das adoções. Os critérios de inclusão destes participantes consistiram em trabalhar no Serviço Social Forense e estarem envolvidos nos processos de adoção.

A coleta de dados foi realizada mediante a assinatura do TCLE - Termo de Consentimento Livre e Esclarecido no qual estão elucidadas as condições da pesquisa, em conformidade com os procedimentos éticos estabelecidos pela resolução da lei 466/2012 do Conselho Nacional de Saúde. Esta pesquisa foi submetida ao Comitê de Ética da Universidade do Vale do Itajaí e foi aprovado pelo parecer $n^{\circ} 1.371 .183$ de 16 de dezembro de 2015.

A coleta dos dados foi efetuada com base em uma entrevista semiestruturada e aplicada com os pais e com os profissionais do Serviço Social Forense (MINAYO, 2010). Os procedimentos envolveram inicialmente o contato telefônico com as comarcas das duas cidades da Região do Vale do Itajaí para solicitar a autorização judicial com a finalidade de acesso aos dados processuais (telefone e endereço) dos pais adotivos. Após acesso aos números telefônicos dos pais adotivos, foi feito o contato com estes com o intuito de convidálos para participar do estudo, ocorrendo o agendamento de entrevistas. Também foi feito o contato com os psicólogos e assistentes sociais destas comarcas para posterior entrevista.

Mediante esta perspectiva, a coleta do material foi realizada em data e local previamente estabelecido e acordado com os entrevistados, com duração de aproximadamente uma hora e gravadas, sendo o conteúdo fielmente transcrito para registro formal das informações e posterior análise.

Os dados obtidos nas entrevistas foram analisados através do método de análise de conteúdo por categorias temáticas buscando descobrir os núcleos de sentidos responsáveis por uma comunicação, cuja presença ou frequência indiquem alguma coisa para o objeto analítico visado. Esta análise constituiu-se de três etapas: pré-análise, exploração do material e tratamento dos resultados obtidos e interpretação (MINAYO, 2010).

Os dados passaram inicialmente por uma leitura flutuante, procurando perceber se todos os aspectos levantados no roteiro estavam presentes bem como se eles continham as características essenciais do universo pretendido (representatividade), além de ter sido 
observada a homogeneidade e a pertinência dos conteúdos analisados. Após esta etapa, foram determinadas unidades de registro (palavras chave ou frases), unidades de contexto, recortes, a forma de categorização, a modalidade de codificação e os conceitos teóricos mais gerais que orientaram a análise. Em seguida, foi realizado o tratamento dos resultados obtidos e a interpretação de onde puderam ser feitas inferências.

\section{Apresentação e discussão dos resultados}

As tabelas abaixo apresentam o perfil dos entrevistados, auxiliando na compreensão dos dados obtidos. Os profissionais entrevistados foram nominados com a letra $\mathrm{E}$ e números de um a seis. Os pais com a letra $\mathrm{P}$ e números de um a cinco, sendo que quando eram casais foram nominados com o mesmo número acrescentando-se na nomenclatura os números 1 e 2 precedidos de um ponto final.

Quadro 1: Perfil dos profissionais entrevistados

\begin{tabular}{|c|c|c|c|c|c|c|}
\hline Nome & Sexo & Idade & Profissão & $\begin{array}{c}\text { Ano de } \\
\text { formação }\end{array}$ & $\begin{array}{c}\text { Ano do início } \\
\text { do trabalho } \\
\text { no fórum }\end{array}$ & $\begin{array}{c}\text { Tempo de } \\
\text { trabalho } \\
\text { no fórum }\end{array}$ \\
\hline E1 & Feminino & 50 anos & Assistente social & 1988 & 1991 & 25 anos \\
\hline E2 & Feminino & 36 anos & Psicóloga & 2003 & 2009 & 7 anos \\
\hline E3 & Feminino & 34 anos & Assistente social & 2005 & 2011 & 5 anos \\
\hline E4 & Masculino & 41 anos & Psicólogo & 2003 & 2009 & 7 anos \\
\hline E5 & Feminino & 41 anos & Assistente social & 2007 & 2011 & 5 anos \\
\hline E6 & Feminino & 51 anos & Psicóloga & 1987 & 2002 & 14 anos \\
\hline
\end{tabular}

Os dados apresentados na tabela acima, indicam que dos seis profissionais entrevistados, cinco são mulheres. Destas, duas são psicólogas e três são assistentes sociais, e um é homem, sendo este psicólogo. A média de idade dos profissionais corresponde a aproximadamente 42 anos, considerando que todos têm mais de cinco anos de experiência profissional no Serviço Social Forense. Assim, considerando o tempo em que estes profissionais atuam com adoção, pode-se dizer que eles possuem um expertise na área da adoção. Segundo Galvão, Perfeito e Macedo (2011), expertise refere-se à capacidade de realizar particularmente bem uma tarefa específica de um domínio, sendo esta adquirida através da prática ou estudo individual. Ainda segundo este autor, pesquisas apontam uma performance superior do expert em relação a pessoas com menos estudo e experiência na área. Esta diferença pode ser explicada pelo fato de que experts geralmente tem como base um 
conhecimento sólido na sua área especifica, apresentando melhor memória para "material significante" e buscando soluções para problemas de modo mais elaborado, empregando diferentes estratégias para resolvê-los.

Quadro 2: Perfil dos pais entrevistados

\begin{tabular}{|c|c|c|c|c|c|c|c|}
\hline Nome & Sexo & Idade & Profissão & $\begin{array}{c}\text { Outros } \\
\text { filhos } \\
\text { biológicos }\end{array}$ & $\begin{array}{c}\text { Outros } \\
\text { filhos } \\
\text { adotivos }\end{array}$ & $\begin{array}{c}\text { Histórico } \\
\text { de } \\
\text { adoção } \\
\text { na } \\
\text { família }\end{array}$ & $\begin{array}{c}\text { Idade } \\
\text { da(s) } \\
\text { Criança(s) } \\
\text { no } \\
\text { momento } \\
\text { da adoção }\end{array}$ \\
\hline P1 & Feminino & $\begin{array}{c}39 \\
\text { anos }\end{array}$ & $\begin{array}{c}\text { Assistente } \\
\text { social }\end{array}$ & Sim & Não & Não & 8 anos \\
\hline P2.1 & Feminino & $\begin{array}{c}40 \\
\text { anos }\end{array}$ & Empresária & Não & Não & Sim & $\begin{array}{c}\text { Recém- } \\
\text { nascido }\end{array}$ \\
\hline P2.2 & Masculino & $\begin{array}{c}43 \\
\text { anos }\end{array}$ & Empresário & Sim & Não & Não & $\begin{array}{c}\text { Recém- } \\
\text { nascido }\end{array}$ \\
\hline P3 & Feminino & $\begin{array}{c}48 \\
\text { anos }\end{array}$ & Professora & Não & Não & Sim & $\begin{array}{c}\text { Recém- } \\
\text { nascido }\end{array}$ \\
\hline P4.1 & Masculino & $\begin{array}{c}45 \\
\text { anos }\end{array}$ & $\begin{array}{c}\text { Supervisor } \\
\text { de }\end{array}$ & Não & Não & Sim & $\begin{array}{c}3 \text { e 6 } \\
\text { anos* }\end{array}$ \\
\hline P4.2 & Feminino & $\begin{array}{c}41 \\
\text { anos }\end{array}$ & Autônoma & Não & Não & Sim & 3 e 6 anos \\
\hline P5 & Feminino & $\begin{array}{c}37 \\
\text { anos }\end{array}$ & Manicure & Não & Não & Sim & $\begin{array}{c}\text { Recém- } \\
\text { nascido }\end{array}$ \\
\hline
\end{tabular}

* As crianças de 3 e 6 anos foram adotadas simultaneamente pelo casal P4.

A tabela acima, com base nos dados obtidos nas entrevistas com os pais adotivos, aponta que dos sete participantes, apenas dois são homens e cinco são mulheres. A média de idade deles é aproximadamente 42 anos sem muita dispersão. As profissões exercidas pelos participantes são diversificadas. A maioria dos participantes não possui outros filhos biológicos e nem adotivos, porém apresentam histórico de adoção na família. A partir da tabela também é possível perceber que apesar de terem ocorrido duas adoções tardias, a adoção de recém-nascidos ainda é predominante, assim como aponta a literatura (MOTTA, 2001). Segundo o IBGE, no Brasil no ano de 2009, 47,3\% das famílias eram compostas por casais com filhos. Este número vem diminuindo desde o ano de 2001, quando 53,3\% das famílias seguiam este padrão. Ainda segundo o IBGE, no ano de 2011, entres os casais brasileiros com filhos, $32,48 \%$ possuía um adulto referência com idade entre 35 e 49 anos, 
indo de encontro com o perfil dos pais entrevistados.

Para realizar a análise do conteúdo apreendido por meio das entrevistas com os pais e os profissionais, foi realizada a organização dos sentidos encontrados nas falas dos participantes em categorias definidas de acordo com os objetivos deste estudo. Sendo assim, foram estabelecidas quatro categorias, sendo que as duas primeiras categorias possuem três subcategorias:

Quadro 3: Categorias de análise

\begin{tabular}{|l|l|}
\hline 1. PROCESSO DE ADOÇÃO & $\begin{array}{l}\text { Esta categoria descreve como pais e profissionais veem o } \\
\text { processo de adoção, seus trâmites, sua duração e o que } \\
\text { fazem durante esta etapa (preparação, reuniões, entrega de } \\
\text { documentos). }\end{array}$ \\
\hline 1.1. Motivação & $\begin{array}{l}\text { Esta subcategoria descreve os principais pontos elencados } \\
\text { como fatores influentes na decisão da adoção. }\end{array}$ \\
\hline 1.2. Dificuldades & $\begin{array}{l}\text { Esta subcategoria refere-se aos obstáculos enfrentados } \\
\text { durante o processo de adoção. }\end{array}$ \\
\hline 1.3. Preparação & $\begin{array}{l}\text { Esta subcategoria busca descrever a maneira com que os } \\
\text { pretendentes se preparam para receber a criança, } \\
\text { abrangendo desde as etapas de preparação obrigatórias do } \\
\text { processo de adoção até as ações pessoais. }\end{array}$ \\
\hline 2. ESTÁGIO DE CONVIVÊNCIA & $\begin{array}{l}\text { O estágio de convivência refere-se ao período de } \\
\text { adaptação da criança à família e da família à criança } \\
\text { juridicamente estabelecido e que culmina na aprovação } \\
\text { final da adoção. }\end{array}$ \\
\hline 2.1. Sua importância & $\begin{array}{l}\text { É a descrição da relevância do estágio de convivência para } \\
\text { o sucesso das adoções. }\end{array}$ \\
\hline 2.2. Dificuldades das crianças & $\begin{array}{l}\text { Aponta os principais obstáculos vivenciados pelas crianças } \\
\text { e identificados pelos pais durante o processo de adaptação } \\
\text { das crianças à nova família. }\end{array}$ \\
\hline 2.3. Dificuldade dos pais & $\begin{array}{l}\text { Esta subcategoria aponta os principais obstáculos } \\
\text { vivenciados e identificados pelos pais durante o processo } \\
\text { de adaptação das crianças à nova família. }\end{array}$ \\
\hline 3. CONTRIBUIÇÕES DOS GRUPOS DE & $\begin{array}{l}\text { Esta categoria busca determinar os principais aspectos } \\
\text { existentes no grupo e identificados como importantes para } \\
\text { que as adoções sejam bem sucedidas. }\end{array}$ \\
\hline $\begin{array}{l}\text { 4. FATORES QUE CONTRIBUEM PARA } \\
\text { O SUCESSO DAS ADOÇÕES }\end{array}$ & $\begin{array}{l}\text { Esta categoria elenca aspectos que foram considerados } \\
\text { fatores importantes para o sucesso das adoções. }\end{array}$ \\
\hline
\end{tabular}

A seguir são apresentadas as categorias que emergiriam a partir da interpretação dos dados coletados por meio das entrevistas com os participantes do estudo. 


\section{O processo de adoção}

Esta categoria foi dividida em três subcategorias, pois os aspectos emergidos nos discursos tanto dos profissionais quanto dos pais, abrangeram diversos fatores inerentes ao processo de adoção, mas que circundaram três grandes temas principais em comum: a motivação, as dificuldades e a preparação, havendo rica diversidade de temas e opiniões.

\subsection{Motivação}

Toda decisão de adotar uma criança está relacionada a um motivo responsável pela realização de atitudes que impliquem concretização da adoção. Nos dados colhidos, a principal motivação apresentada foi a impossibilidade de ter filhos, como pode-se constatar com as falas dos participantes P4.1: O que nos motivou à adoção, é, (pensou) problemas de saúde, digamos assim, problemas congênitos" e $\mathrm{P} 3:$ "Eu não engravidava, eu não engravidava, fui fazer tratamento,[...] a gente fica bem abalada com aquilo, uma incapacidade da gente [...], e aí eu conversei com meu marido sobre isso (adoção)". As falas dos profissionais também evidenciaram este fator, de acordo com E1: "Para ter filhos [...] grande parte (dos que adotam) é de casais impossibilitados de gestar" e E2: "A adoção ainda é, [...] na maioria dos casos, ainda é pela dificuldade ou impossibilidade de gerar filhos biológicos".

Outras motivações como ampliação do número de filhos e o desejo de não ficar sozinho também foram relatadas pelos profissionais como motivos menos frequentes, conforme evidenciado na fala de E2: “Muitos (pais) vem para ampliar a quantidade de filhos, mesmo podendo ter os filhos biológicos". Dentre os pais entrevistados que divergiram da impossibilidade de gerar filhos, um casal apontou como motivo ampliar o número de filhos e outro quis ter filhos por adoção, pois já era um desejo anterior ao casamento.

Segundo Vescovi (2014), existem diferentes motivos que levam as pessoas à adoção. Dentre estes motivos estão: o desejo de ter filhos sem precisar passar pelo processo de gravidez, por medo ou por razões estéticas; a vontade de ser pai ou mãe mesmo não tendo um parceiro, assim como o desejo de ter filhos por casais homoafetivos. Outras razões incluem: perda recente de um filho ou de um parente próximo, ampliação do número de filhos, necessidade de preencher a solidão ou ter companhia na velhice, e ideias filantrópicas ou altruístas, como o desejo de dar um lar a crianças e/ou adolescentes que não possuem família ou estejam em situação de risco. Porém, corroborando os dados coletados neste estudo, a literatura indica que a principal motivação para a adoção é a infertilidade. A partir da 
frustração de não poder gerar filhos biológicos, os casais buscam suprir a lacuna da maternidade e paternidade, através da adoção (SCHETTINI; AMAZONAS; DIAS, 2006; HUBER; SIQUEIRA, 2010; VESCOVI, 2014).

Os profissionais salientaram que muitos casais esperam adquirir a estabilidade financeira para ter filhos, condição que os faz ter um longo período de união sem filhos e idade mais avançada quando optam pela paternidade. A tabela com a idade dos pais participantes revela que a média de idade destes quando adotaram era de 41,8 anos, o que corrobora as falas dos profissionais ao afirmarem que a adoção é, na maior parte das vezes, último recurso diante da impossibilidade de gerar filhos.

\subsection{Dificuldades do processo}

Ao ingressar para adoção, os pretendentes passam por dois períodos até que ocorra a sua concretização: a) o período processual de habilitação; b) o tempo de espera na fila do Cadastro Nacional de Adoção. Entre os principais obstáculos elencados na concretização da adoção durante a sua primeira etapa, estão o longo tempo de espera e a burocracia do processo, conforme evidenciado nas falas de P3: "Еu acho que assim, mais uma ansiedade, né." e P2.1: "A questão burocrática que demora muito. Tu desanimas, depois tu te anima de novo, tu tens esperança [...]. O processo é vagaroso e até doído".

Os autores Schettini, Amazonas e Dias (2006), Gondim et al. (2008) e Huber e Siqueira (2010) afirmam que a grande burocracia dos processos de adoção é um fator ansiogênico e desmotivador para os pretendentes, pois o longo tempo de espera traz à tona um grande sofrimento e desgaste emocional associado às lembranças de tentativas frustradas de gravidez e de exercer a paternidade. A demora do processo também influencia nas idealizações dos pretendentes sobre a criança e como será o relacionamento com ela, aumentando fantasias e questionamentos acerca da adoção.

Já os profissionais relataram que observam como dificuldade a longa espera (principalmente decorrente do perfil escolhido pelos pretendentes), a ilegalidade envolvendo algumas adoções, a demora para a destituição familiar, o não acesso dos pretendentes ao cadastro de adoção e a falta de profissionais específicos acompanharem os processos de adoção, conforme ilustram as falas de E1: "O tempo de demora é muito grande e isso gera uma frustração bastante grande." e E6: "Não existem psicólogos e assistentes sociais exclusivos para a adoção, falta de pessoal específico para a adoção". 
A literatura pesquisada alega que na história do Brasil, sempre houve casos de adoção ilegal, popularmente conhecida como "adoção à brasileira". Diante disso, o processo de adoção está passando por modificações em seus dispositivos de fiscalização e monitoramento, entre eles o Cadastro Nacional de Adoção, em busca de melhorias, maior efetividade e segurança para o andamento das ações. Apesar destas medidas, ainda ocorrem muitos casos de ilegalidade, normalmente motivados pela pressa dos pretendentes em receber uma criança, pela impunidade dos seus praticantes ou ainda pela percepção da delonga para a concretização das adoções via processo legal. As crianças em condição favorável à adoção passam mais tempo presas entre a família biológica e os abrigos do que na fila de adoção propriamente dita. Isso acontece pela burocracia envolvendo a destituição familiar e este fato acaba por retardar a entrada das crianças no Cadastro Nacional de Adoção, distanciando-as dos perfis desejados pelos pretendentes. E assim, dificultando a consolidação das adoções (FONSECA, 2006; SCHETTINI; AMAZONAS; DIAS, 2006; GONDIM et al., 2008; HUBER; SIQUEIRA, 2010; SANTOS, 2010; BORGES, 2014).

Durante as entrevistas, também foi possível identificar na fala de alguns pais a questão da religiosidade enquanto estratégia de enfrentamento da ansiedade gerada pelo tempo de espera no processo de adoção, conforme demonstram as falas de P4.2: "Porém, quanto a isso, eu estava muito tranquila porque eu achava que era tudo no tempo de Deus, né? Ele sabe o momento certo." E P5: "Eu acho que é a hora que Deus quer que eu seja mãe que vai acontecer, não é a hora que o médico quer nem a hora que teu corpo quer. É a hora que Deus quer".

A literatura aponta que a religiosidade é uma estratégia de coping (enfrentamento) de situações estressantes (PANZINI; BANDEIRA, 2007; BRITO, 2011; BORGES; SANTOS; PINHEIRO, 2015; BORGES, 2015). Segundo Panzini e Bandeira (2007) e Borges (2015), estas estratégias de coping religioso contribuem para a diminuição da ansiedade e de sintomas depressivos, aliviando consequências emocionais negativas de situações emergenciais ou estressantes vividas. O coping religioso auxilia também na ressignificação dos acontecimentos marcantes para o sujeito e para o enfrentamento de perdas e desafios.

\subsection{Preparação}

Os dados colhidos para esta subcategoria demonstram que há uma divergência de opinião entre pais e profissionais em relação à preparação para a adoção. Os pretendentes pouco se prepararam para a adoção, preocupando-se em descrever as leituras que fizeram e os 
vídeos que assistiram por iniciativa própria. A fala da maioria dos pais é semelhante a fala de P3: "Eu li alguma coisa por fora, e assim, li alguma coisa, na verdade na internet [..]".

Os profissionais apontaram, além das estratégias descritas pelos pais, aspectos técnicos e recursos legais importantes para a preparação, principalmente o curso de preparação obrigatório por lei, questões como a avaliação psicológica, o estudo social e a participação nos GEAAs, segundo evidenciado nas falas de E2: "Hoje o preparo é, pela lei. Obrigatoriamente eles têm que passar por um curso de preparação", E5: "A preparação começa a partir do momento em que eles ingressam com a ação, curso...depois estudo social, avaliação psicológica, a indicação da participação no grupo, leituras...” e E3: “O preparo deles por parte do fórum é um curso, que se chama oficialmente de Programa de Preparação dos Pretendentes [...]. Depois do estudo social e avaliação psicológica [...]. Então por parte do fórum, são essas as (pensou), é oferecido esse tipo de preparação, mas eu entendo que os casais deveriam procurar ler, deveriam continuar fazendo uma preparação individual por conta deles, independente do que o fórum oferece...".

Os aspectos levantados pelos profissionais vão ao encontro do que a literatura aponta como crucial para a desconstrução destas significações de adoção: é por meio da atuação dos profissionais e da mobilização de órgãos governamentais que novas formas de reflexão surgem, sendo necessária a promoção de ambientes em que ocorra a orientação, reflexão e discussão do assunto com os pretendentes e sua família extensa, para dar suporte ao grupo familiar e estimular as adoções (AMIM; MENANDRO, 2007; PURETZ; LUIZ, 2007; PAULI; ROSSETTI-FERREIRA, 2009; VALÉRIO; LYRA, 2014).

Para Pauli e Rossetti-Ferreira (2009) e Valério e Lyra (2014), a construção de significados é um processo de construção e desconstrução em constante transformação, presente em um espaço que é influenciado por questões culturais, coletivas e pessoais do contexto no qual os sujeitos estão inseridos. Existe um conjunto de fatores que direcionam certos sentidos e barram a construção de outros significados para a adoção. Dentre estes fatores estão aspectos relacionados à influência e ao peso de fatores biológicos da família de origem e do contexto de vivência. Assim como questões associadas aos inúmeros fatores advindos da organização e da dinâmica da instituição familiar, como os mitos acerca da maternidade/paternidade e filiação, bem como as características das organizações (escola, instituições de abrigamento, fórum, entre outros). Outro aspecto relevante são as políticas públicas que regulamentam os assuntos acima citados.

Esta diferença pode estar relacionada aos discursos de naturalização da paternidade (mito do amor materno) vigentes em nossa sociedade, nos quais não há a necessidade de 
preparação para se ter filhos, sejam eles biológicos ou não. De acordo com a tabela 1, há também outro fator importante que corresponde à experiência dos profissionais: todos os profissionais têm mais de cinco anos de experiência no Serviço Social Forense, o que agrega experiência e conhecimento às suas práticas profissionais.

\section{Estágio de convivência}

Os sentidos que emergiram nos discursos tanto dos profissionais quanto dos pais nos dados colhidos para a análise desta categoria abordaram diversos assuntos referentes ao estágio de convivência, mas que circundaram três grandes temas principais em comum: sua importância, as dificuldades das crianças e as dificuldades dos pais. A emergência destes temas tornou necessária a subdivisão desta categoria em três subcategorias abarcando tais aspectos.

\subsection{Sua importância}

Os pais demonstraram em suas falas uma preocupação em descrever o estágio de convivência, detalhando os seus sentimentos e sensações durante o período, conforme ilustram as falas a seguir: "O estágio de convivência foi tranquilo, com dias às vezes mais corridos, assim, nada fora do normal" (P3) e P1: "[...] foi tranquilo, como é hoje desde o começo" ou P4.1: "Foi uma mudança da água para o vinho! ”. Já os profissionais salientaram em suas falas que a importância deste período deve-se ao fato de este ser um momento de orientação e acompanhamento da família, fundamentais para a adaptação e formação de vínculos afetivos, como demonstram as falas: “[...] se houve a possibilidade de uma construção de laços afetivos, se estão conseguindo estabelecer uma relação de afeto ou não" (E1), E2: "Porque é um momento de adaptação que é fundamental que se acompanhe muito mais para prevenir problemas no relacionamento do que para dizer deu certo ou não deu" e E5: "[...] fundamental pra que assim eles se reconheçam um ao outro e ali se possa estabelecer uma relação de afeto".

A literatura corrobora as diferentes perspectivas existentes entre os pais em relação ao estágio de convivência, afirmando que entre eles é comum, neste período, sentimentos e ideias conflitantes, pois estas são fruto de idealizações e desejos construídos ao longo de sua vivência familiar e conjugal, bem como de todo o processo de preparação para a adoção vivenciado em nossa sociedade: há um forte dualismo entre aqueles que romantizam a 
adoção, achando que tudo será perfeito e aqueles que pensam que filho adotivo é sinônimo de relações problemáticas (GHIRARDI, 2009; RIEDE; SARTORI, 2013; GOES, 2014).

Pode-se inferir a partir disto que não há consenso entre pais e profissionais quanto à importância do estágio de convivência: percebe-se no discurso dos pais a presença de sentidos diversos ao se referirem ao estágio de convivência, pois estes atribuíram significações contraditórias em sua descrição desta etapa como um "período de mudanças" e "período tranquilo". Destaca-se também o foco dos pais nos seus sentimentos e na maneira que vivenciaram o período, em detrimento da importância desta etapa para as crianças. Entretanto, os discursos dos profissionais trazem à tona a preocupação com o estabelecimento de vínculos e o olhar voltado para as crianças, atribuindo maior relevância à maneira como elas vivenciam o estágio da adoção.

Segundo Goes (2014), o estágio de convivência é considerado uma etapa basilar para a consolidação da adoção e é um período pouco reconhecido pelo imaginário infantil, onde não existem documentos e/ou sentenças e no qual o convívio com a nova família já é a certeza da adoção. Diante disto, torna-se uma etapa crucial para a criação e fortalecimento de relações afetivas, bem como de criação de novas histórias e construção de identidades. A literatura ressalta que os adultos envolvidos no processo de adoção (pais, profissionais e membros do Poder Judiciário) são as partes conscientes e maduras da ação, e devem, portanto, estarem atentos às dificuldades que possam enfrentar para a consolidação da adoção. Eles devem buscar orientação, informações e dispositivos legais para problematizá-la e desconstruir estereótipos e preconceitos existentes na sociedade. Desta forma, estarão procurando incluir a criança na família adotiva e na sociedade de maneira plena e integral, conforme preconizado pelo ECA - Estatuto da Criança e do Adolescente (FONSECA, 2006; GHIRARDI, 2009; SILVA; SILVA, 2012; RIEDE; SARTORI, 2013; GOES, 2014).

\subsection{Dificuldades das crianças}

Nesta subcategoria, poucos pais identificaram dificuldades de adaptação com seus filhos (três dos entrevistados) e quando as descreveram, consideraram de fácil resolução e de menor dificuldade que as dificuldades vivenciadas por eles próprios, como apontam as falas de P1: "Problemas muito com ela a gente não teve, ela teve muita dificuldade na escola, [...] pra menina foi muito tranquilo" e P4.2: “Eles, é (pensou) muito fácil se adaptar. Porque eles querem atenção, querem carinho". 
Entretanto, os profissionais discordaram dos pais, elencando diversas situações e salientando que as dificuldades vivenciadas pelas crianças são muito maiores que as dos pais, conforme as falas de E1: “( a criança) ser tirada de um lugar que ela está habituada, onde ela está, e ir para um outro ambiente totalmente diferente de pessoas que ela nunca viu, eu acho até que elas surpreendem muito positivamente. Mas eu acho que para elas, é extremamente complicado, porque muda alimentação, muda hábitos, muda tudo" e E2: "Muitas vezes, as crianças reagem com agressividade, regressão de comportamentos, às vezes algumas dificuldades escolares, dificuldades relativas à alimentação, ou comer demais [...], mas acredito que a maior dificuldade seja a confiança, a segurança de que vai ser sempre, de que vai dar tudo certo, de que essas pessoas vão amar essa criança e que ela vai amar essas pessoas. É o enfrentamento do novo".

As falas dos profissionais demonstram ciência da dificuldade dos pais em identificar os possíveis obstáculos da adaptação de seus filhos e preocupação quanto ao bom andamento da adoção, diante de sua experiência profissional e da quantidade de novas situações enfrentadas pelas crianças. Entre as principais dificuldades vivenciadas pelas crianças, eles citam a resistência para aceitar as regras estabelecidas pelos cuidadores, rotinas familiares muito diferentes da que estavam acostumadas, perfis parentais muito rígidos ou pouco acolhedores, aspectos não elencados pelos pais.

A literatura pesquisada não apresenta referências claras sobre a dificuldade dos pais em identificar os possíveis obstáculos das crianças, limitando-se em salientar a importância da orientação e preparo destes para este período de adaptação. Os estudos sobre o tema corroboram as falas dos profissionais acerca das dificuldades enfrentadas pelas crianças em seu processo adaptativo, como a regressão de comportamentos, agressividade, ansiedade, medo de rejeição e resistência para aceitar mudanças nas regras e rotinas a que estavam acostumadas (AMIM; MENANDRO, 2007; SOLON, 2008; OTUKA; SCORSOLINICOMIN; SANTOS, 2009; RODRIGUES, 2010).

Outro fator pouco explorado pelos pais foi o histórico da criança: crianças adotadas muitas vezes já viveram com outras famílias e em abrigos, carregam consigo afetos e desafetos importantes para a construção de sua identidade, necessitando de um tempo para “despedirem-se" e assimilarem a nova vida. Para Rodrigues (2010), a criança que parte para a adoção comumente passou por diferentes contextos e experiências (família biológica, abrigo, família adotante, Sistema Judiciário, entre outros) e na maior parte do tempo, sem compreender o que estava acontecendo. Estes contextos e experiências fizeram parte de sua história e marcaram a construção de sua identidade. Desta forma, a autora salienta a 
necessidade e a importância de preservar o passado da criança, dando oportunidades para que ela converse sobre ele e vivencie os momentos de transição e de despedida. Conhecer e respeitar seu histórico e permitir que a criança vivencie o luto pela mudança de vida a que estava acostumada, seja ela com a família anterior ou no abrigo, é um aspecto de muita relevância para o bom andamento do processo de adaptação da criança, conforme aponta a fala de E1: "mas a gente acha também que precisa de um tempo para o luto, não pode ser uma coisa muito rápida. Saiu da casa dos pais e no outro mês já está em outra família”.

\subsection{Dificuldades dos pais}

Os pais indicaram como dificuldades a adaptação às mudanças na rotina do casal com a chegada dos filhos e mudanças na vida profissional, como demonstra a fala de P3: "Era só nós dois, então pensar assim, chegar em casa e me sentar, não vou fazer nada, não deu mais pra fazer né. A gente muda a rotina da gente em favor deles" e P4.2: "De início foi uma loucura (risos). É, porque era só nós dois, e de repente mais dois, duas crianças, nossa!![...]Nós temos a nossa vida profissional que continua, com muito mais carga, porque aí tu tens que trabalhar mais, né, tu tem eles que tem que dar carinho, tu tens que...a carga aumenta muito, nê". Já os profissionais levantaram questões como falta de maturidade por parte dos pretendentes, busca pela satisfação dos seus desejos ao invés dos da criança e dificuldades para compreender as necessidades das crianças frente à nova realidade, como mostram as falas de E1: "Eu acho que ainda há muito o interesse do casal. Os casais ainda pensam em satisfazer os seus desejos e não os desejos da criança[...]. A gente percebe muitas vezes que é falta de maturidade de lidar com toda uma situação" e E5: "Às vezes são dificuldades de compreensão das necessidades da criança frente a todas essas mudanças que aconteceram na vida dela[...] nesse momento, exige-se muito mais do adulto do que da criança, porque ele deveria ter a capacidade de compreender que aquela criança talvez tenha passado por experiências que não foram tão boas".

Percebe-se um descompasso entre as falas dos pais e dos profissionais, visto que estes salientam a importância da atenção à criança e o papel dos pais na adoção, atentando para a compreensão e satisfação das necessidades dos filhos acima das necessidades dos pais, enquanto que aqueles referem seus desejos e as suas necessidades frente às mudanças advindas da chegada dos filhos. Otuka, Scorsolini-Comin e Santos (2009) e Rodrigues (2010) afirmam que os pretendentes ao se tornarem pais, juntamente com a sua família e seus novos membros passam por uma reestruturação de sua dinâmica familiar, o que requer de todos a 
capacidade de adaptação e a maleabilidade para lidar com novas demandas e situações. Tanto a criança quanto os pais, irmãos e familiares necessitarão de apoio mútuo e em alguns casos orientação de profissionais para reconhecer e lidar com os entraves que esta mudança no ciclo familiar representa.

Os profissionais salientaram ainda que toda inserção de um novo membro familiar traz dificuldades à família, independentemente de ser uma maternidade biológica ou adotiva, conforme ilustra a fala de E1: "São os mesmos problemas de uma maternidade biológica, mas com uma diferença, não tem vínculo (ênfase) [...]".

A parentalidade é construída mediante significações expressas pela sociedade e a partir da experiência pessoal de cada membro em sua própria família, das situações que vivenciaram com seus pais e avós, por exemplo. Também depende das idealizações do casal durante a espera pelo filho, adotivo ou biológico, e do modo como serão estabelecidas as relações entre eles após sua chegada, exigindo de todos os membros flexibilidade e negociação de limites e valores, tanto para o estabelecimento de vínculos quanto para o estabelecimento da identidade e papel de cada membro (OTUKA; SCORSOLINI-COMIN; SANTOS, 2009; RODRIGUES, 2010; MARCHETTO, 2010; ZORNIG, 2010).

\section{Contribuição dos GEAAs}

Pais e profissionais apontaram que o grupo contribui para amenizar a ansiedade vivenciada pelos pretendentes durante o tempo de espera pela adoção, conforme demonstram as falas de P2.1: “Ajudou na ansiedade, né, (pensou) de como saber que é ter um filho em casa, se a gente realmente estava preparado pra ter um filho de coração[...]" e E2: "Como uma forma muitas vezes de minimizar a ansiedade que é gerada por esse tempo de espera [...]". Também salientaram as contribuições do grupo para a preparação para a adoção, sendo que os pais valorizaram a troca de experiências que ocorre nos grupos e os profissionais as orientações de parentalidade, questões jurídicas e socialização de conhecimentos sobre adoção, como ilustram as falas de P1: "A gente vai aprendendo com os outros, cada um traz uma experiência diferente e a gente vai compartilhando [...]", P4.1: "Mas essa troca de experiências com os outros, a (pensou) participação, realmente a participação no grupo é que dá esse suporte para as pessoas[..]", E2: "Como uma forma de se preparar especificamente para assuntos que são relacionados à adoção e também, às questões de maternidade, paternidade, filiação[...] Então, eu entendo que sim, que o grupo, os grupos de maneira geral (ênfase) auxiliam muito, também nas orientações de questões jurídicas" e E5: 
“Então, ele (o grupo) auxilia nesse sentido, a partir de, digamos assim, uma transmissão de conhecimentos, que profissionais detém sobre a temática e nesses espaços é socializado e discutido, é uma troca mesmo, que acontece ali".

Percebe-se diante das falas que os pais atribuíram maior valor ao apoio emocional prestado pelo grupo por meio da troca de experiências e do convívio com casais que se encontram na mesma situação do que para a aquisição de conhecimentos e preparação para a paternidade. Os profissionais, por outro lado, enfatizaram a possibilidade de troca de experiências e aquisição de conhecimentos oriundas da participação dos pais nos GEAAs, bem como o suporte emocional propiciado pelos participantes. É importante ressaltar que estes grupos possibilitam a discussão em seus encontros tanto dos aspectos elencados pelos pais quanto pelos profissionais, o que demonstra o seu papel contribuinte para o sucesso das adoções.

Segundo a literatura, os GEAAs podem ser considerados grupos de apoio/suporte. Este tipo de grupo constitui-se como um recurso que possibilita a troca de experiências e reflexões entre pessoas que vivem situações semelhantes, gerando sentimentos de compreensão e apoio mútuo entre os participantes, permitindo assim que eles possam aliviar seus sentimentos de ansiedade, solidão e incertezas. A semelhança entre as situações vivenciadas pelos membros facilita a intimidade, a troca de confidências e a confiança entre eles, assim como favorece a manifestação de sentimentos. Através do apoio emocional, informações e orientações, este tipo de grupo permite aos participantes terem uma melhor percepção da situação que estão vivendo e diminuição das fantasias a ela relacionadas. Ele também apresenta o potencial para prevenir o desenvolvimento de comportamentos mal adaptados e estimular comportamentos saudáveis, oportunizando a aprendizagem e o crescimento pessoal em clima de compartilhamento e aceitação. Para os integrantes desses grupos, a principal contribuição da sua participação está na crença de que eles podem ser mais ajudados por quem já viveu ou está vivendo uma experiência como a sua, do que por pessoas que que nunca passaram por ela (OLIVEIRA et al., 2008; ALVAREZ et al., 2012).

Para Sequeira e Stella (2014), os GEAAs permitem aos pretendentes à adoção, assim como aos pais por adoção, trocar experiências com pessoas em situações semelhantes, desvendando algumas dúvidas, desmistificando alguns assuntos, também trabalhar sentimentos e emoções despertados pelo processo de adoção, ressignificar conflitos e afetos, contribuindo até mesmo para que os pretendentes alterem o perfil da criança a ser adotada. Temas como a revelação da adoção para a criança, o longo tempo de espera e a ansiedade gerada por ele, a revolta com a burocracia da justiça brasileira, o medo de que a família 
biológica queira novamente a criança e a adoção tardia são importantes de serem discutidos nestes grupos.

Diante das contribuições elencadas, pais e profissionais sugerem a realização de mais reuniões (atualmente é realizada um encontro por mês) e a continuidade do grupo após a adoção, como apontam P5: “O grupo eu achava que devia até ter mais reuniões, porque uma vez por mês é pouco. Eu achava assim, que os casais que adotaram deviam se conhecer, eu sempre queria trocar ideias" e E5: "Acho que ele (o grupo) poderia contribuir muito mais no sentido de talvez pensar em criar espaços mais específicos, por exemplo: grupos de pós adoção, pra discutir pós adoção, com pretendentes, com pais”.

\section{Fatores que contribuem para o sucesso das adoções}

Os pais listaram como fatores que contribuíram para o sucesso das suas adoções o apoio da família, o bom relacionamento conjugal, bem como a congruência de objetivos do casal e a preparação por meio do diálogo, conforme ilustram P1: “A família toda junto, todo mundo unido, todo mundo preparado, a conversa [...], eu acho que a gente preparar bem, a gente ser uma família unida, isso colabora bastante" e P4.2: "Eu acho que o casal tem que estar muito preparado, e o casal tem que se dar muito bem (ênfase) [...]porque é um baque".

Entre os profissionais, a preparação também apareceu como fator importante, porém abrangendo outros aspectos como as questões jurídicas da adoção, o perfil dos pretendentes e a participação no grupo, implicando ainda a atuação do profissional durante o processo de adoção, como indicam E2: "De modo geral, a preparação[...].É o conhecimento histórico da criança, o conhecimento histórico processual inclusive, toda a etapa de preparação, aproximação, orientações e depois de concretizada a guarda, pra fins de adoção, o acompanhamento do estágio de convivência", E4: "A maneira como tu conduz a avaliação, também a maneira de tu conduzir a própria adoção..." e E5: "A preparação, leituras, de textos que discutem o tema, a própria participação no grupo". Percebe-se que os profissionais consideraram de grande importância a sua atuação no processo de adoção, avaliando-se como responsáveis pelo sucesso ou fracasso destas. Eles atribuem a si a responsabilidade por acreditarem na influência de suas orientações, avaliações e decisões durante todo o processo de preparação e por responderem às entidades maiores, como o Poder Judiciário Brasileiro, que cobra e procura justificativas para possíveis falhas na consolidação da adoção. 
A literatura ressalta a responsabilidade dos profissionais diante da consolidação da adoção: há grandes expectativas depositadas neles pelos pais, Poder Judiciário e às vezes pela própria criança. Quando a adoção não se concretiza (devolução), surgem sentimentos de culpabilização e impotência: procura-se idetificar o que deu errado e todos pedem explicações aos profissionais, pois a devolução é compreendida pelo Judiciário como um segundo abandono da criança, que deve voltar ao abrigo. Uma boa avaliação realizada pelos profissionais, feita com cautela e atenção aos adotantes, bem como o bom andamento do estágio de convivência, que deve ser um período de orientação e de formação de vínculos afetivos amenizam as chances de ocorrer uma devolução. Além destas medidas, o Poder Judiciário Brasileiro cogita a possibilidade de punição dos pais pelo duplo abandono (devolução da criança após a consolidação da adoção), por meio do pagamento de penas pecuniárias, visando diminuir a ocorrência de devoluções (FONSECA, 2006; MATOS; HERNANDES; ELOY, 2011; SILVA; SILVA, 2012; RIEDE; SARTORI, 2013; TABORDA, 2014).

Além dos fatores acima citados, o profissional E6 defende que para o sucesso das adoções é necessária a disponibilidade dos profissionais e dos pretendentes para a participação nos cursos, grupo e orientações, sugerindo a inserção de mais profissionais no ambiente jurídico para atuar exclusivamente com adoção. Deste modo, este participante acredita que as avaliações serão mais rápidas e o curso de preparação mais intenso.

De acordo com Matos, Hernandes e Eloy (2011), Silva e Silva (2012) e Taborda (2014), para a efetivação da adoção são necessários inúmeros fatores, como as avaliações bem realizadas, participação em GEAAs e ainda o acompanhamento das famílias e o tempo de convivência para experiência (estágio de convivência), pois é nesse período de preparação que as partes vão conviver, trocar experiências e estabelecer vínculos afetivos, examinando as suas escolhas, desejos e anseios.

\section{Considerações finais}

Este estudo buscou investigar a contribuição do trabalho realizado pelos GEAAs sobre adoção no sucesso das adoções, visto que este é um tema pouco abordado pela literatura existente.

De acordo com os resultados deste estudo, foi possível definir algumas questões relacionadas as contribuições dos GEAAs. Os participantes apontaram que o grupo contribui para amenizar a ansiedade vivenciada pelos pais adotivos enquanto pretendentes durante o 
tempo de espera pela adoção, constituindo-se como uma rede de apoio emocional, promovendo a troca de experiências entre estes e pais adotivos, construindo conhecimentos sobre o assunto. O grupo contribui ainda na medida em que auxilia na orientação dos pretendentes tanto nas questões legais quanto nas questões relativas à paternidade, e também auxilia fomentando a participação nos cursos preparatórios realizados pelo Poder Judiciário.

Além do papel significativo do grupo na consolidação das adoções, outros aspectos foram elencados pelos profissionais como contribuintes para o sucesso das adoções: a adaptação das crianças e dos pretendentes às mudanças em suas rotinas e no próprio relacionamento conjugal, bem como o desejo mútuo de exercer a paternidade por parte dos pretendentes.

Pais e profissionais descreveram o período de estágio de convivência como um período de adaptação para a nova configuração familiar, marcado por dificuldades para os pais e para as crianças, sendo considerado apenas pelos profissionais como uma etapa de extrema relevância para a consolidação das adoções.

A partir da perspectiva dos profissionais, também pode-se inferir que contribuem para o sucesso da adoção o trabalho da equipe forense pautado na orientação dos pretendentes, no fortalecimento de vínculos e laços afetivos na família adotiva e na preparação à parentalidade por meio dos cursos do Judiciário.

Diante da literatura pesquisada, constatou-se que no período pós-adoção há o surgimento de comportamentos regressivos na criança, sentimento de culpa, vulnerabilidade e comportamentos de imitação, expressões que quando não trabalhadas podem culminar no fracasso das adoções. Desta forma, concluímos que o trabalho para a formação e fortalecimento de vínculos entre a criança e seus familiares adotivos, bem como o acompanhamento do período pós-adoção pela equipe forense são fatores preponderantes para o sucesso das adoções.

Uma das limitações encontradas para a realização deste trabalho foi a literatura sobre o tema que evidencia o fracasso das adoções ou as devoluções das crianças, discorrendo pouco sobre os casos de sucesso e o papel dos GEAAs. Isto pode estar relacionado ao fato da Nova Lei da Adoção (lei 12.010/09) ter publicação recente e às constantes mudanças no processo de adoção.

Diante dos resultados do estudo observou-se a necessidade de contratação de um maior número de profissionais forenses pelo Poder Judiciário para o trabalho com adoção, de modo a contribuir para que o processo seja acompanhado com maior agilidade. Sugere-se 
ainda o incentivo às práticas de orientação e preparação à parentalidade, tanto biológica quanto adotiva, visto que, com este estudo pôde-se concluir que estas práticas, bem como as trocas de experiências possuem um papel significativo no sucesso das adoções, na consolidação dos laços afetivos e na formação da família.

Há poucas políticas públicas que envolvam o trabalho e a preparação para a parentalidade, tanto biológica quanto adotiva, bem como uma legislação desconhecida relacionada à adoção. Cabe ao psicólogo, nos lugares em que estiver inserido - fórum, conselhos municipais, instituições de ensino - atuar de modo ético e responsável, visando o bem-estar das crianças, pretendentes e pais adotivos. É dever da psicologia problematizar temas como a adoção, quebrar padrões e ressignificar os conceitos e conhecimentos existentes, fomentando a discussão das etapas legais de adoção, dos meios para a sua consolidação, realizando congressos, oficinas e participando de GEAAs. Por isso também, propomos a realização de novos estudos abordando esta temática, visando dar à adoção a visibilidade necessária para a quebra de padrões e ressignificações de conceitos e conhecimentos existentes, contribuindo de maneira mais significativa para o sucesso das adoções.

\title{
STUDY AND ADOPTION SUPPORT GROUPS AND THE SUCCESS OF ADOPTIONS
}

\begin{abstract}
The adoption in Brazil has gone through many changes over time, occurring in different forms and representations. With the aim to contribute to a change of perspective, Study and Adoption Support Groups have arisen. This study seeks to analyze the work done by these groups, examining the possible contributions of the participation of adoptive parents or adoption claimants, as well as to analyze, through the perspective of forensic professionals, the possible factors that contribute to this success. This is a qualitative approach research, it involves parents engaged in the adoption process and the staff of the Forensic Social Work. The data collection used semi-structured and open interviews, its data were subsequently analyzed using thematic categories. The results found point to the fact that study and adoption support groups create an important network of emotional support during the waiting time for adoption in that they ease the anxiety felt by claimants and encourage the exchange of experiences and socialization of the knowledge on the subject. The main contributing factors to the success of adoption are guidance, exchange of experience, participation in meetings and preparatory courses conducted by the judiciary. With this study, it was concluded that the practical guidance and preparation for parenthood, as well as exchanges of experience have a significant role in the success of adoptions.
\end{abstract}

Key-words: Adoption; Child; Support groups. 


\title{
GRUPOS DE ESTUDIO Y APOYO A LA ADOPCIÓN Y EL ÉXITO DE LAS ADOPCIÓNES
}

\begin{abstract}
Resumen
La adopción en Brasil ha cambiado con el tiempo, ocurriendo en diferentes formas y representaciones. Buscando contribuir a un cambio de perspectiva surgieron los Grupos de Estudio y Apoyo a la Adopción. Esta investigación buscó examinar el trabajo realizado por estos grupos, examinando las posibles contribuciones de la participación de los padres adoptivos o los solicitantes de adopción en el grupo y la opinión de los profesionales del Trabajo Social Forense en relación a los posibles factores que contribuyen para el éxito de la adopción. Se trata de una investigación cualitativa, que envolvió como participantes los padres adoptivos y profesionales del Trabajo Social Forense. La colección de datos se realizó a través de entrevistas semiestructuradas y abiertas. Los datos fueron analizados posteriormente utilizando categorías temáticas. Los resultados muestran que los grupos de estudio y apoyo a la adopción constituyen como una importante red de apoyo emocional durante el tiempo de espera para su aprobación, ayudan a aliviar la ansiedad sentida por los solicitantes, fomenta el intercambio de experiencias y la socialización de conocimiento sobre el tema. Los principales factores que contribuyen al éxito de las adopciones son orientación, el intercambio de experiencias, a participación en reuniones y cursos de preparación llevados a cabo por el poder judicial. Con este estudio, se concluyó que la práctica de orientación y preparación para la parentalidad, así como el intercambio de experiencias tienen un papel importante en el éxito de las adopciones.
\end{abstract}

Palabras clave: Adopción; Niño; Grupos de apoyo.

\section{REFERÊNCIAS}

ALVAREZ, S. Q.; et al. Grupo de apoio/ suporte como estratégia de cuidado: importância para familiares de usuários de drogas. Rev. Gaúcha Enferm., Porto Alegre, v. 33, n.2, p. 102$108,2012$.

AMIM, I. D.; MENANDRO, P. R. M. Preferências por Características do Futuro Filho Adotivo Manifestadas por Pretendentes à Adoção. Interação em Psicologia, Curitiba, v. 11, n. 2, p.241-252, jul/dez. 2007.

BERLINI, A. C. Comissão Especial de Direito à Adoção - Ordem dos Advogados do Brasil OAB (Comp.). Adoção: Um ato de amor. São Paulo, 2012. Disponível em: $<$ http://www.oabsp.org.br/comissoes2010/direito-adocao/cartilhas>. Acesso em 10 abr. 2015.

BORGES, M. S.; SANTOS, M. B. C.; PINHEIRO, T. G. Representações sociais sobre religião e espiritualidade. Revista Brasileira de Enfermagem, Brasília, v. 68, n. 4, p. 609616, ago. 2015.

BORGES, N. C. Adoção à brasileira face à família moderna. 2014. 61 f. TCC (Graduação) - Curso de Direito, Centro Universitário de Brasília, Brasília, 2014.

BORGES, R. S. P. C. A religião em psicoterapia: Experiências de terapeutas com clientes religiosos. 2015. 109 f. Dissertação (Mestrado) - Curso de Psicologia, Instituto Universitário de Ciências Psicológicas, Sociais e da Vida, Lisboa, 2015. 
BRASIL. Lei $\mathbf{n}^{\circ} \mathbf{8 . 0 6 9}$, de 13 de julho de 1990. Disponível em $<$ http://www.planalto.gov.br/ccivil_03/Leis/18069.htm>. Acesso em 10 jun. 2015.

BRASIL. Tribunal De Justiça do Estado do Amazonas. 25 de maio - Dia Nacional da Adoção. $2014 . \quad$ Disponível em $<$ http://www.tjam.jus.br/index.php?option $=$ com_content $\&$ view $=$ article \&id=6326:25-de-maiodia-nacional-da-adocao\&catid=478:cij-projetos $\mathbf{\&}$ Itemid=502> Acesso em 17 abr. 2015.

BRITO, H. L. Coping Religioso: implicações para a prática clínica. 2011. 107 f. Dissertação (Mestrado) - Curso de Psicologia, Universidade Católica de Goiás, Goiânia, 2011.

CAMPOS, N. M. V. Vara da Infância e Juventude do Distrito Federal. Adoção Tardia: Características do estágio de Convivência. Distrito Federal, 2012. Disponível em: $<$ http://www.tjdft.jus.br/cidadaos/infancia-e-juventude/textos-e-artigos $>$. Acesso em 27 abr. 2015.

CAVAlCANTI, G. G. Os Direitos da Criança e do Adolescente e o Cadastro Nacional da Adoção: reflexões interdisciplinares sobre os efeitos da matriz bioparental. Veredas Favip, Vale do Ipojuca, v. 7, n. 2, p. 43-58, jul. 2014.

DIAS, C. M. S. B.; SILVA, R. V. B.; FONSECA, C. M. S. M. S. A Adoção de Crianças Maiores na Perspectiva de Pais Adotivos. Contextos Clínicos, Rio Grande do Sul, n. 1, p. 2835, janeiro/junho, 2008.

EBRAHIM, S. G. Adoção Tardia: Altruísmo, Maturidade e Estabilidade Emocional. Psicologia: Reflexão e Crítica, n. 1, v. 14, p. 73-80, 2001.

FONSECA, C. Da circulação de crianças à adoção internacional: questões de pertencimento e posse. Caderno Pagu, Campinas, n. 26, p. 11-43, jun. 2006.

FREIRE, F. Apresentação. In: LANSER, F. M. Adoção: Pais adotivos, suas angústias e incertezas. Blumenau: Nova Letra, 2002.

GALVÃO, A.; PERFEITO, C.; MACEDO, R. Desenvolvimento de expertise: um estudo de caso. Revista Diálogo Educacional, Curitiba, v. 11, n. 34, p.1015-1033, 2011.

GHIRARDI, M. L. A. M. A devolução de crianças adotadas: ruptura do laço familiar. Pediatria Moderna, São Paulo, v. 45, n. 2, p.66-70, 2009.

GOES, A. E. D. Criança não é brinquedo! A devolução de crianças e adolescentes em processos adotivos. Synthesis: Cadernos do Centro de Ciências Sociais da Universidade do Estado do Rio de Janeiro, Rio de Janeiro, v. 7, n. 1, p.85-93, 2014.

GONDIM, A. K.; et al. Motivação dos pais para a prática da adoção. Boletim de Psicologia, São Paulo, v. 58, n. 129, p. 161-170, dez. 2008.

GONÇALVES, H. S.; BRANDÃO, E. P. Psicologia Jurídica no Brasil. $3^{\text {a }}$ ed. São Paulo: Nau Editora, 2011.

HUBER, M. Z.; SIQUEIRA, A. C. Pais por adoção: a adoção na perspectiva dos casais em filla de espera. Psicologia: Teoria e Prática, São Paulo, v. 12, n. 2, p. 200-216, 2010. 
INSTITUTO BRASILEIRO DE GEOGRAFIA E ESTATÍSTICA - IBGE. Pesquisa Nacional por Amostra de Domicílios 2001/2011. In: Banco de Dados Séries Estatísticas e Séries Históricas.

$<\mathrm{http}$ ://seriesestatisticas.ibge.gov.br/lista_tema.aspx?op=0\&no=0>. Acesso em 20 de maio de 2016.

KIRCH, A. T.; COPATT, L. C. Criança e adolescente: a problemática da adoção e posterior devolução às casas de acolhimento. Prisma Jurídico, São Paulo, v. 13, n. 1, p.13-36, 2014.

MACÊDO, L. E. M. L. A dinâmica perversa na adoção: interrogando sobre filiação. Revista Latinoamericana de Psicopatologia Fundamental, São Paulo, n. 17, v. 3, p. 696-705, setembro, 2014.

MARCHETTO, M. V. Mudanças no ciclo de vida familiar a partir da adoção. $2010.52 \mathrm{f}$. Monografia (Especialização) - Curso de Psicologia, Familiare Instituto Sistêmico, Florianópolis, 2010.

MATIVE, S. N. M.; RAMPAZZO, C. C. S. As novas regras para a adoção e o papel do assistente social judiciário. In: Anais do Encontro de Iniciação Científica do Centro Universitário Antonio Eufrásio de Toledo. Intertemas, Presidente Prudente, 2010.

MATTOS, M. P.; HERNANDES, M. A. F.; ELOY, C. B. Adoção e devolução: a criança devolvida. In: Congresso de Psicologia da UNIFIL, IV, 2011, Londrina. Encontros da Psicologia. Londrina: Unifil, 2011, p. 01-13.

MAUX, A. A. B.; DUTRA, E. A Adoção no Brasil: algumas reflexões. Estudos e Pesquisas em Psicologia, Rio de Janeiro, n. 02, p. 356-372, maio/agosto, 2010.

MINAYO, M. C. S. O desafio do conhecimento: pesquisa qualitativa em saúde. 12 ed. São Paulo: Hucitec, 2010.

MOTTA, M. A. P. Mães Abandonadas: a entrega de um filho em adoção. $3^{a}$ ed. São Paulo: Cortez Editora, 2001.

NABINGER, S. Adoção: o encontro de duas histórias. Santo Ângelo: FURI, 2010.

OLIVEIRA, L. M. A. C.; et al. Uso de fatores terapêuticos para avaliação de resultados em grupos de suporte. Acta Paul Enferm., v. 21, n.3, p. 432-438, 2008.

OTUKA, L. K.; SCORSOLINI-COMIN, F.; SANTOS, M. A. A configuração dos vínculos na adoção: uma atualização no contexto Latino-Americano. Revista Brasileira Crescimento e Desenvolvimento Humano, São Paulo, v. 19, n. 3, p.475-486, dez. 2009.

PANZINI, R. G.; BANDEIRA, D. R. Coping (Enfrentamento) Religioso/ Espiritual. Revista de Psiquiatria Clínica, São Paulo, v. 34, n. 1, p.126-135, 2007.

PAULI, S. C.; ROSETTI-FERREIRA, M. C. Construção das dificuldades de aprendizagem em crianças adotadas. Cadernos de Pesquisa, São Paulo, v. 138, n. 39, p.881-895, dez. 2009.

PURETZ, A; LUIZ, D. E. C. Adoção Tardia: Desafios e Perspectivas na Sociedade Contemporânea. Revista Emancipação, Ponta Grossa, v. 2, n. 7, p.277-301, 2007. 
RIEDE, J. E.; SARTORI, G. L. Z. Adoção e os fatores de risco: do afeto à devolução das crianças e adolescentes. Perspectiva, Erechim, v. 37, n. 138, p.143-154, jun. 2013.

RODRIGUES, V. P. Adoção Tardia. 2010. 55 f. TCC (Graduação) - Curso de Direito, Universidade do Extremo Sul Catarinense - Unesc, Criciúma, 2010.

SANTOS, C. P.; et al. Adoção por pais solteiros: desafios e peculiaridades dessa experiência. Psicologia: Teoria e Prática, São Paulo, n. 2, v. 13, p. 89-102, 2011.

SANTOS, D. C. S. Adoção tardia: uma realidade em Sergipe. Revista da Esmese, Aracaju, n. 14, p.183-208, dez. 2010.

SCHETTINI, S. S. M.; AMAZONAS, M. C. L. A.; DIAS, C. M. S. B. Famílias adotivas: identidades e diferenças. Psicologia em Estudo, Maringá, v. 11, n. 2, p.285-293, maio/ago.2006.

SEQUEIRA, V. C.; STELLA, C. Preparação para a adoção: grupo de apoio para candidatos. Psicologia: Teoria e Prática, São Paulo, n. 01, v. 16, p. 69-78, janeiro/abril, 2014.

SILVA, L. A.; MESQUITA, D. P.; CARVALHO, B. G. E. Investigando o processo de adoção no Brasil e o perfil dos adotantes. Revista de Ciências Humanas, Florianópolis, v. 44, n. 1, p. 191-204, abr. 2010.

SILVA, J. C. B; SILVA, E. C. B. Adoção: da idealização ao fracasso. In: Congresso Internacional Interdisciplinar em Sociais e Humanidades, 2012, Niterói. Anais do Coninter. Niterói: Coninter, 2012, p. 01-17.

SOLON, L. A. G. Conversando com a criança sobre adoção. São Paulo: Casa do Psicólogo, 2008.

TABORDA, C. R. Adoção: a família no processo adotiva. 2014. 32 f. TCC (Graduação) Curso de Psicologia, Departamento de Humanidades e Educação, Universidade Regional do Noroeste do Estado do Rio Grande do Sul, Ijuí, 2014.

VALENTE, J. Família Acolhedora: as relações de cuidado e de proteção no serviço de acolhimento. São Paulo: Paulus, 2013.

VALÉRIO, T. A. M.; LYRA, M. C. D. P. A Construção Cultural de Significados sobre Adoção: um processo semiótico. Psicologia e Sociedade, Minas Gerais, v. 26, n. 3, p.716$725,2014$.

VESCOVI, G. Motivações para Adotar e Relacionamento na Família Adotiva: Análise de um Filme Infantil. Diaphora, Rio Grande do Sul, v. 14, n.1, p. 66-73, jan/ago. 2014.

ZORNIG, S. M. A. Tornar-se pai, tornar-se mãe: O Processo de Construção da Parentalidade. Tempo Psicanalítico, Rio de Janeiro, v. 42, n. 2, p.453-470, 2010.

WEBER, L. Adote Com Carinho: Um Manual Sobre Aspectos Essenciais da Adoção. 1a ed. Curitiba: Juruá, 2011. 
Data de recebimento: 30/09/2016

Data de aceite: 06/07/2017

\section{Sobre as autoras:}

Mariana de Oliveira Bortolatto é Psicóloga pelo Curso de Psicologia da Universidade do Vale do Itajaí. Atualmente atua com psicologia clínica e orientação profissional. Endereço Eletrônico: mariana_bortolatto@hotmail.com

Victória Niebuhr Loos trabalhou por dois anos como mediadora no Serviço de Mediação Familiar de Brusque. Tem experiência na área de Psicologia. Atualmente faz mestrado com ênfase em Saúde e Desenvolvimento Psicológico pela UFSC e participa das atividades de extensão do Laboratório de Psicologia Cognitiva Básica e Aplicada (LPCOG) do curso de psicologia da UFSC. É bolsista da CAPES-DS no mestrado. Endereço Eletrônico: victorialoos@hotmail.com

Josiane da Silva Delvan possui graduação em Psicologia pela Universidade do Vale do Itajaí (1992), graduação em Pedagogia pela Universidade do Vale do Itajaí (1990), mestrado em Psicologia pela Pontifícia Universidade Católica do Rio Grande do Sul (2000) e doutorado em Psicologia pela Universidade de São Paulo (2007). Atualmente é coordenadora do curso de Psicologia da Universidade do Vale do Itajaí e professora na disciplina de Psicologia do Desenvolvimento Humano, Orientadora de Estágio Curricular Obrigatório e de Trabalho de Iniciação Científica. Tem experiência na área de Psicologia em Desenvolvimento de crianças, atuando principalmente nos seguintes temas: crianças, parentalidade e saúde mental na infância. Endereço Eletrônico: josidelvan@univali.br 